\title{
Investigating the Apparent Teleconnection between Cosmic-Ray Muon Flux over Jamaica and Large-Scale Climate Phenomena That Impact the Caribbean
}

\author{
Lawrence Patrick Brown 1,2, John Charlery3, Mitko Voutchkov² \\ ${ }^{1}$ Meteorological Service, Kingston, Jamaica \\ ${ }^{2}$ Physics Department, University of the West Indies, Mona, Jamaica \\ ${ }^{3}$ Department of Computer Science, Mathematics and Physics, University of the West Indies, Cave Hill, Barbados \\ Email: larro1924@yahoo.com
}

How to cite this paper: Brown, L.P., Charlery, J. and Voutchkov, M. (2019) Investigating the Apparent Teleconnection between Cosmic-Ray Muon Flux over Jamaica and Large-Scale Climate Phenomena That Impact Caribbean. Atmospheric and Climate Sciences, 9, 626-649. https://doi.org/10.4236/acs.2019.94039

Received: July 16, 2019

Accepted: October 20, 2019

Published: October 23, 2019

Copyright (อ 2019 by author(s) and Scientific Research Publishing Inc. This work is licensed under the Creative Commons Attribution International License (CC BY 4.0).

http://creativecommons.org/licenses/by/4.0/

\section{c) (i) Open Access}

\begin{abstract}
The apparent teleconnection between cosmic-ray muon flux over a base point in the Caribbean is discussed against the background of an extensive record of indices representing large-scale climatic phenomena, but limited cosmic-ray muon flux data. Many investigators have shown that large-scale climate phenomena influence sub-seasonal and seasonal climate variability, especially in the northern hemisphere and their impacts on the Caribbean are well documented. These climatic phenomena that impact the Caribbean include, but are not limited to, the El Nino Southern Oscillation, the Quasi-Biennial Oscillation, the North Atlantic Oscillation, and the Arctic Oscillation which is now being investigated. Although strong statistical correlation between variables over non-contiguous regions are not absolute as proof of teleconnections, the correlation strength can be used as an indication of its existence. The data gathered at the Mona Campus of the University of the West Indies, in Jamaica, using a simple QuarkNet 6000 muon detector over the period September 2011 to September 2013, showed an apparent significant relationship with these climatic indices. This suggests that cosmic-ray muon flux might be linked to the behavior of the climate phenomena and therefore can be used as a climate or meteorological index over the Caribbean.
\end{abstract}

\section{Keywords}

Cosmic-Ray Muon, University of the West Indies Mona, Climate

Phenomena, Teleconnections 


\section{Introduction: Muon Teleconnection}

Outside of the well-known diurnal atmospheric cycles, other oscillation time scales vary from weeks to months, and years. The Madden-Julian Oscillation (MJO), El Nino and Southern Oscillation (ENSO) and Quasi-Biennial Oscillation (QBO) are just a few examples. It has been argued by researchers such as [1] and [2] that weather and climate phenomena (some of which are strongly correlated to each other), are also linked to cosmic-ray muon flux (CMF). The Caribbean based on its geographic, atmospheric and climatic features-some of which can be argued as being fixed or change very little over time-can be considered as being unique. For example, the highest mountains are found in the central Caribbean over Hispaniola and Jamaica [3] and sea surface temperatures above $28.5^{\circ} \mathrm{C}$ referred to as the Caribbean Warm Pool constitute part of the second largest body of very warm water on earth [4]. Both of these contribute to cloud development, influence the movement of weather systems and the intensity of rainfall across the central Caribbean (especially). These and other features such as tropopause height and the geomagnetic cut off rigidities, do not have frequent significant change in values, but also have an impact on cosmic ray muon flux and make the region and sub-region unique.

Yet another significant feature in the Caribbean region is the mid-summer drought (MSD) which is a relative lull in rainfall activity during the period late June-early August of each year. In their effort to understand this phenomena [5] suggest a link between the MSD and sub-micron aerosols during this period. [6] also argued that a large aerosol flux of anthropogenic origin occurred during June, July and August. This they argue contains large amounts of submicron aerosol and suggest that this increased amount leads to a reduction in rainfall during the period. [7] explains that atmospheric aerosols affect precipitation by reducing the amount of radiation reaching the ground and therefore suppress precipitation in shallow and short-lived clouds. They also argued that this is due to increased heat added to the clouds in which they mix and leads to reduced cloud coverage as a result of evaporation. [8] argued a connection between galactic cosmic-ray (GCR) and ENSO trends, while [9] highlighted the emergence of Cosmoclimatology and a link between GCR, cloud condensation nuclei (CCN) and cloud formation based on satellite observed clouds. However, this has been very controversial as [10] in their review of this cloud-climate-cosmic ray flux hypothesis, found strong arguments on both sides, proving the need for more affirmative investigations. These arguments are of much interest to Caribbean researchers since CCN liberated by GCR are below normal sizes $(<20 \mathrm{~nm})$ and rainfall over the Caribbean over the last 20 to 30 years is generally on the decline.

Muons are sub-atomic particles produced when cosmic radiation enter the earth's atmosphere and interact with nuclei and other aerosols. The initial reaction generates Pions and Kaons which decay immediately to form muons, neutrinos, and electrons. Authors such as [11], [12], [13] and [14] have suggested 
that some teleconnections exist between cosmic-ray muons flux (CMF) and meteorological phenomena based on the physical relationship between atmospheric temperature and pressure. According to [15], over the past 30 years, the NAO has been trending towards a more positive phase, which indicates warmer and wetter conditions over eastern USA. [16] argued that the abnormally high solar activity between solar cycles 23 and 24 has caused the longest solar minima in over 80 years and an unusually small solar maxima of cycle 24 . This has resulted in very weak solar activity, the highest flux of galactic cosmic rays and relatively small amounts of energetic particle events. [17] also argues the existence of a link between solar activity and cosmic-ray flux, by stating that a more active Sun has a stronger associated solar wind, which reduces the flux of cosmic rays reaching the Earth. [18] was among the first to show that the variation in cosmic ray muon flux (CMF) is conspicuously related to latitude, altitude and other factors such as the strength of geomagnetic cut off rigidity (GCOR). [19] have also shown that the diurnal anisotropy (unequal physical properties along different axes) of cosmic-ray has both latitudinal and longitudinal dependences and both arguments suggest that CMF can be specifically linked to parameters over a base point region.

Observed trends in the factors such as latitude, GCOR, tropopause height, temperature and pressure which have been shown to influence cosmic ray muon flux decrease polewards. However, air density and the general flux in cosmic ray muons increase polewards. [9] and [20] go further and also suggest that while clouds below $3 \mathrm{~km}$ are uncorrelated at mid and high latitudes with cosmic-rays, a strong correlation exists with clouds at low latitudes. This, therefore, gives impetus to this study as we seek a regional or Caribbean CMF perspective. Our hypothesis is therefore that extra-atmospheric factors can result in significant events such as ground level enhancements (GLE) and Forbush decrease (Fds). Apart from these phenomena the contribution to changes in cosmic ray muon flux would not be significant. The dominant factors that will modify the muon flux in the troposphere are therefore a) geospatial-that is the area of the base point region, the GCOR and the location of detector above sea level-and b) the geo-meteorological factors-that is the frequency and type of weather systems, the height of the tropopause and in our case the presence of the Caribbean warm pool (sea surface temperature anomalies). These are the factors that will impact atmospheric temperature and pressure and by extension the muon flux. These factors are also susceptible to being influenced by global and regional teleconnections. Furthermore, if the cosmic-ray muon flux can be linked to large scale circulation and by extension be used to explain the variability distinguished from small-scale localized effects, then as suggested by [21] it could also be used to account for $10 \%-20 \%$ of the total seasonal variance (depending on season considered).

Establishing linkages between atmospheric and climate variables within standardized base points with other elements from non-contiguous regions is described as teleconnection. According to [22], these base points can also be des- 
ignated by researchers as well as be determined by objective research methods. The teleconnections between meteorological and climate phenomena are very important as they are responsible for early detection and evolution of substantial variations in weather and climate events. The linkage between large-scale climate phenomena from non-contiguous regions can also be connected to severe weather conditions in the Caribbean and by itself be reason enough for robust investigations. Correlations between various climate phenomena were therefore done over the long term to determine the strength of their relationship and verified what was widely documented. [22] argued that teleconnection maps can be constructed using parameters measured at the surface (for example pressure) and that statistical correlation can be used as an indication of the teleconnection strength. The decision to use large scale climate phenomena was deliberate as several studies have shown that the Caribbean has been impacted by various climate phenomena. [23] for example, argued that the interannual variability of Caribbean rainy season was strongly influenced by both the tropical Atlantic and the nearby tropical and equatorial pacific. The primary question we sought to answer was whether there exists an apparent link between the large-scale climate phenomena which impact Caribbean climate and cosmic-ray muon flux over the Caribbean by using Jamaica as a proxy. The following sections give further background on this discussion.

\section{Teleconnection Base Point and Domains}

In the broadest sense, Caribbean countries are those which border the Caribbean Sea. The sub-divisions include the Greater Antilles, which include Jamaica in the northwestern section, and the Lesser Antilles which include Barbados located outside the chain of islands in the east. The area designated as "base point" is one established by the Meteorological Service, Jamaica (MSJ) as the "severe weather grid" (hereinafter the SWG). This area is bounded by coordinates $14^{\circ} \mathrm{N} /$ $71^{\circ} \mathrm{W}, 14^{\circ} \mathrm{N} / 83^{\circ} \mathrm{W}, 21^{\circ} \mathrm{N} / 83^{\circ} \mathrm{W}$ and $21^{\circ} \mathrm{N} / 71^{\circ} \mathrm{W}$ with Jamaica almost at its centre [24]. Several important studies of the region have described different geographical areas as the Caribbean. For example [25] while investigating the link between early-season Caribbean rainfall and $\mathrm{El} \mathrm{Nino+1} \mathrm{year} \mathrm{used} \mathrm{the} \mathrm{latitudinal}$ range $5^{\circ} \mathrm{N}$ to $28^{\circ} \mathrm{N}$ and longitude $60^{\circ} \mathrm{W}$ to $90^{\circ} \mathrm{W}$. [26] in their study using 35 stations over the region referenced Barbados $\left(13.10^{\circ} \mathrm{N} / 59.50^{\circ} \mathrm{W}\right)$ as the most southern and farthest east, Green Turtle Cay Bahamas $\left(26.75^{\circ} \mathrm{N} / 77.32^{\circ} \mathrm{N}\right)$ as the most northern and Paso Real De San Diego $\left(22.55^{\circ} \mathrm{N} / 83.30^{\circ} \mathrm{W}\right)$ as the most westerly station to examine Caribbean teleconnections. Figure 1 is a schema of the region with SWG.

This study therefore, had 3 main components. The first was to establish a base region (the SWG) as described earlier (Figure 1). This specifies a designated reference area for the data gathered and provides a Caribbean context. The second component was the selection of the non-contiguous areas and large scale climate indices for these areas. The third component was the data analysis and 


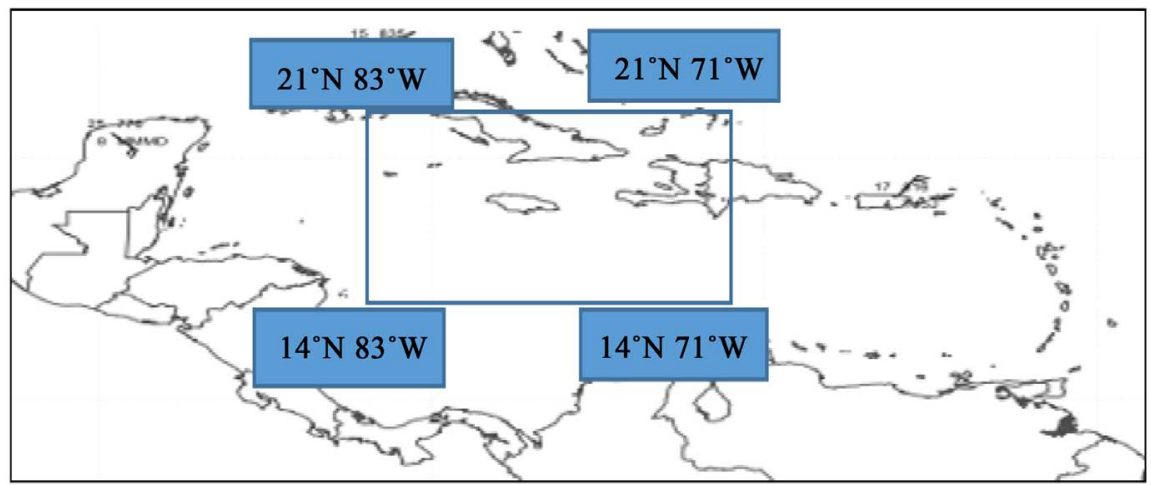

Figure 1. Schematic diagram of Jamaica Severe Weather Grid with coordinates $21^{\circ} \mathrm{N} /$ $83^{\circ} \mathrm{W}, 21^{\circ} \mathrm{N} / 71^{\circ} \mathrm{W}, 14^{\circ} \mathrm{N} / 83^{\circ} \mathrm{W}, 14^{\circ} \mathrm{N} / 71^{\circ} \mathrm{W}$.

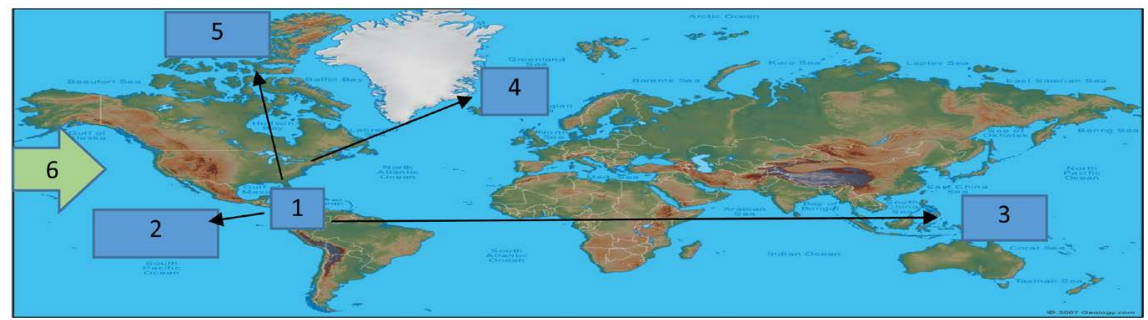

Figure 2. Map identifying approx. source regions of various indices and base point. The Caribbean is location 1, ENSO is location $2 \& 3$, location $4 \& 5$ is the NAO \& AO while 6 is the QBO which is above the earth and extend entire Tropics. Map source, worldmap.com.

the completion of the statistical correlation between the indices representing the climatic phenomena, base point rainfall (using Jamaica monthly rainfall), and cosmic-ray muon flux. The large scale climate phenomena chosen to represent non-contiguous areas were the Quasi-Biennial Oscillation, (QBO), the El Nino (EN), La Nina (LN), the Southern Oscillation (SO), the North Atlantic Oscillation (NAO) and the Arctic Oscillation (AO). Of all these indices the link between the arctic oscillation $\mathrm{AO}$ and Caribbean weather or climate is least or never been explored. The indices representing these climatic phenomena were sourced from various research data sites associated with the US National Oceanic and Atmospheric Administration (NOAA). The period of the study coincided with the mini-maximum of solar cycle 24 and represents a random sample. To assist with linking the various regions involved Figure 2 shows a map of the globe showing the source region of the various indices. The following sections give background on the climate indices used to establish teleconnection, this is followed by discussion regarding data, method, results, and conclusion based on the statistical correlation.

\subsection{Background on Climate Indices for Teleconnection}

\subsubsection{The Quasi-Biennial Oscillation (QBO)}

The QBO is a downward propagating easterly and westerly wind regime that occur within the tropical stratosphere and troposphere. This climate phenomenon 


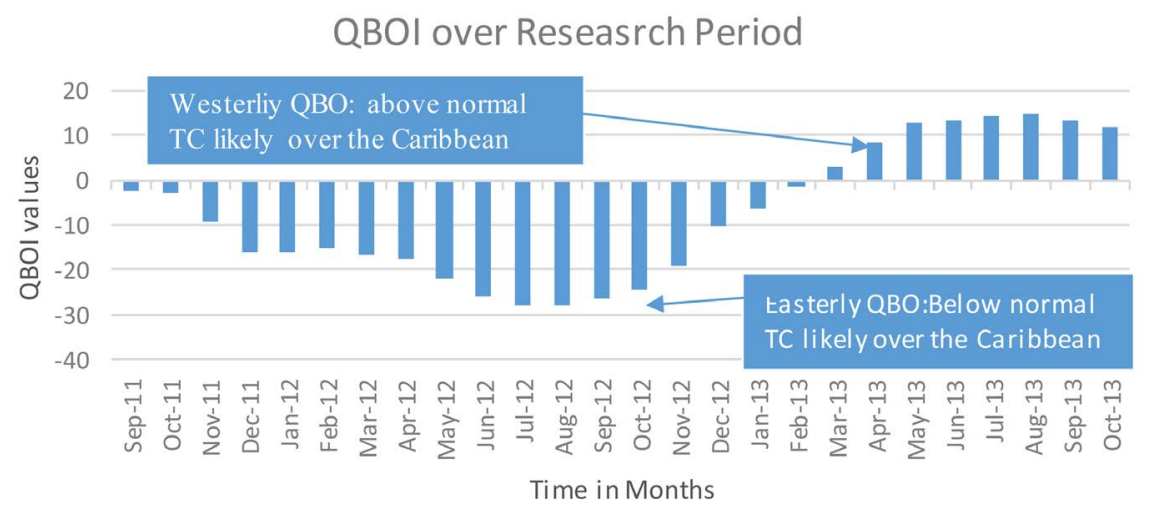

Figure 3. Quasi-Biennial Oscillation Index trend over the study period. Data from: https://www.esrl.noaa.gov/psd/data/correlation/qbo.data.

have both tropical and extra-tropical effects with a wide range of impacts extending as far as the mesosphere [27]. The effects on the Caribbean region is likely from a combination of the tropospheric and stratospheric $Q B O$ influencing the number and intensity of tropical cyclones over the Caribbean. For example, the seasonal number of tropical storms and hurricanes over the Atlantic area, are above normal when the stratospheric QBO is in its westerly phase when compared with its easterly phase [28]. Figure 3 indicates the trend in the stratospheric Quasi-Biennial Oscillation Index (QBOI) during the research period.

The QBO index (QBOI) used in this study was derived from the USA National Center for Environmental Protection and the National Center for Atmospheric Research (NCEP/NCAR) reanalysis data. This represents the zonal average of the $30 \mathrm{mb}$ zonal winds at the equator. As a tropical phenomenon, the QBO dominates the region approximately between $23^{\circ}$ North and South of the Equator. The QBOI, when positive, indicates that the zonal wind is coming from the west (westerlies) while when negative means it is from the east (easterlies). Both the easterlies and westerlies transitions show a strong preference to occur during April to June. It is noteworthy that the QBO influences the breakdown of stratospheric polar vortices during the winter and that the polar vortex in the stratosphere, affects surface weather patterns [27]. [29] goes further to argue that when the $\mathrm{QBO}$ is easterly ( $\mathrm{QBOE}$ ) or negative phase in the lower stratosphere, stronger Madden Julian Oscillation (MJO) activity is likely during the northern hemisphere winter. This relationship they argue has become more evident since the 1980s when a cooling trend in the equatorial lower stratosphere and a warming trend in the equatorial upper troposphere became more evident. This is likely to play an important role in the production of cosmic ray muons and the flux to the surface since cosmic ray muon production starts in the lower stratosphere.

\subsubsection{El Nino Southern Oscillation (ENSO)}

The changes in weather to extreme levels over the globe, from droughts to floods, storms to light stagnant winds and from blizzards to heat waves, have 
been attributed to El Nino Southern Oscillation (ENSO). The El Nino (EN) phenomenon was represented in this study by the Oceanic Nino Index (ONI) which is a 3-month running mean average of sea surface temperatures (SST) over the Nino 3.4 region or $5^{\circ} \mathrm{N}$ to $5^{\circ} \mathrm{S}$ of the equator and longitude $120^{\circ} \mathrm{W}$ to $170^{\circ} \mathrm{W}$ in the Tropical Pacific. When this unusual warming (El Nino) or cooling (La Nino) occurs, it is usually associated with fluctuations in pressure over Darwin, Australia $\left(12.46^{\circ} \mathrm{S}, 130.84^{\circ} \mathrm{E}\right)$ and Tahiti, French Polynesia $\left(17.64^{\circ} \mathrm{S}\right.$, $149.44^{\circ} \mathrm{W}$ ). This pressure fluctuation (or air mass transfers) is referred to as the Southern Oscillation (SO). The distance between the midpoints of the severe weather grid (SWG) in the Caribbean to the midpoint of the Nino 3.4 region in the Tropical Pacific is approximately $7660 \mathrm{~km}$, while the distance to Darwin Australia is approximately $17,010 \mathrm{~km}$ and to Tahiti $8880 \mathrm{~km}$. The Southern Oscillation is represented by the Southern Oscillation Index or SOI. Research surrounding the impact of the ENSO phenomenon on the Caribbean is well documented by authors such as [25] and [26]. The trend in the ONI and SOI over the research period are shown in Figure 4 and Figure 5 below.

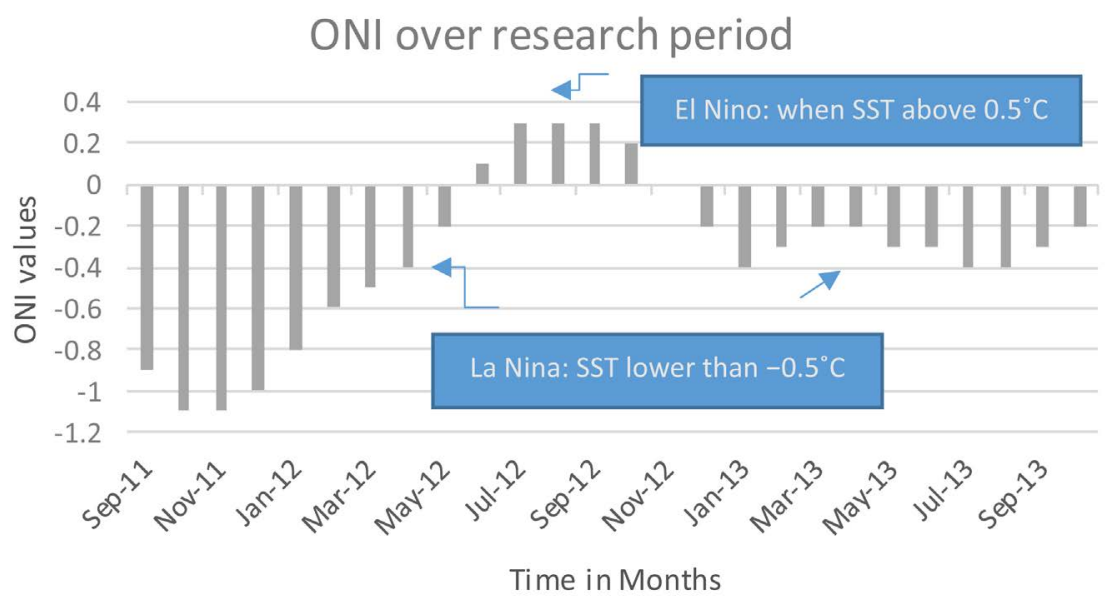

Figure 4. Oceanic Nino Index trend over the study period. Data from: http://origin.cpc.ncep.noaa.gov/products/analysis_monitoring/ensostuff/ONI_v5.php.

\section{SOI over research period}

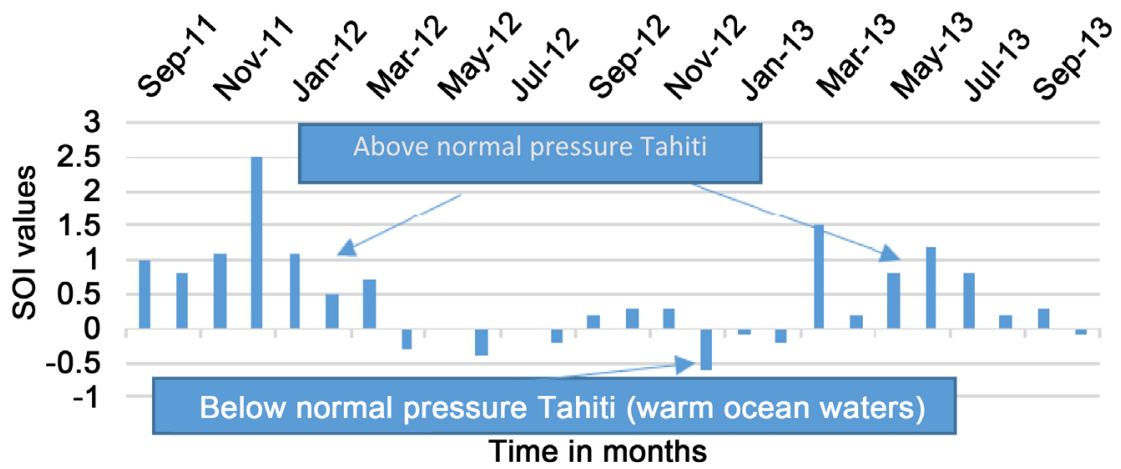

Figure 5. Southern Oscillation Index trend over the study period. Data from: https://www.ncdc.noaa.gov/teleconnections/enso/indicators/soi/data.csv. 
When the Oceanic Nino Index (ONI) is positive (negative) this indicates warming (cooling). This warming (cooling) is based on sea surface temperatures (SST) exceeding $+0.5^{\circ} \mathrm{C}\left(-0.5^{\circ} \mathrm{C}\right)$. Therefore the degree to which these values are exceeded indicates the severity of the phenomena. The SOI also corresponds with changes in SST across the eastern tropical Pacific Ocean. When the SOI is positive, this corresponds with abnormally cold ocean waters across the eastern tropical pacific and is typical of the La Nina phase. This also coincides with above normal atmospheric pressure over Tahiti and below normal pressure over Darwin, on the other hand, negative SOI represents below normal atmospheric pressure over Tahiti and above normal atmospheric pressure over Darwin. This is typical of the El Nino episodes over the eastern tropical Pacific. [30] found that ENSO affected hurricane activities by shifting the location of large scale convection. This is due to the upper tropospheric winds over the Caribbean and tropical Atlantic becoming more westerly. When the lower level tropospheric wind speeds are relatively small, this results in enhanced vertical wind shear and reduced hurricane activity during El Nino hurricane season over the Caribbean. The situation however, is reversed during La Nina episodes.

\subsubsection{North Atlantic Oscillation (NAO)}

The North Atlantic Oscillation (NAO) is a large scale seesawing movement of atmospheric mass between the North Atlantic subtropical high pressure system and the Icelandic low pressure system [31]. [32] also showed that long term upward trend in NAO accounted for much of the surface air temperature warming poleward of $20^{\circ} \mathrm{N}$. The changes in circulation associated with changes in NAO index [32] explained, was based on a difference in sea level pressure between winters with an index value greater than $\pm 1 \mathrm{mb}$. This scenario was similar to the Southern Oscillation (SO) since both involve pressure changes and are linked to sea surface warming. The NAO is however, recognized as a regional phenomenon that influences weather over the Atlantic, with its depth limited to the troposphere. It has been commonly stated that the NAO index, when in a positive phase, results in mild and wet winter conditions over the eastern USA while colder, snowier weather conditions accompany the negative phase. [31] concluded that the influence of the NAO on the rainfall variability pattern over Barbados was dependent on the phase and intensity of ENSO events. While [26] argued that NAO was negatively associated with Caribbean rainfall when the preceding winter was considered and positively associated with rainfall over the southeastern Caribbean (especially during the late summer) when monthly rainfall was considered. Figure 6 shows the trend in the NAO during the study period.

This investigation therefore, is in part, a continuation of the search for teleconnections. In this case, it is between climate phenomena and an extra-atmospheric one (cosmic rays) and its secondary components (cosmic ray muons) that is influenced by atmospheric conditions. For example, the mechanisms that excite 


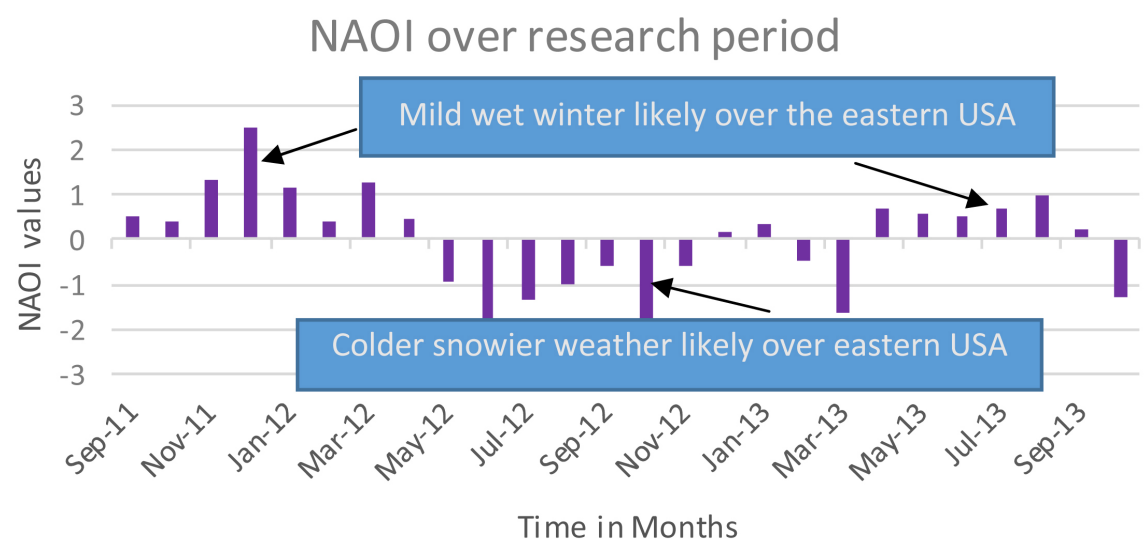

Figure 6. North Atlantic Oscillation Index trend over study period.

Data from: https://www.cpc.ncep.noaa.gov/products/precip/CWlink/pna/nao.shtml.

and sustain the North Atlantic Oscillation (NAO) - one of the notable and earliest discovered patterns-are still being investigated." As [22] stated most eloquently regarding the NAO, "although the structure of the prominent teleconnection patterns has been known for some time, the reasons for their origin are not yet well understood.

\subsubsection{Arctic Oscillation (A0)}

The Arctic Oscillation (AO) is a seesaw in the atmospheric pressure between the Arctic basin and the surrounding zonal ring [33]. [33] also argued that the AO is similar to the NAO with a slightly larger horizontal scale and a higher degree of zonal symmetry. These authors further argued that the NAO is a regional manifestation of the $\mathrm{AO}$, since the $\mathrm{AO}$ is hemispheric. The strength of this argument is that the NAO and AO share similar characteristics due to the geographic area covered and the atmospheric depth occupied by both. [34] suggest however, that the $\mathrm{AO}$ extends into the stratosphere and that this phenomenon is linked to the sudden warming of the stratosphere (aka sudden stratospheric warming or SSW) and the QBO. Both the QBO and the NAO have been shown to influence Caribbean weather due to stratospheric-tropospheric coupling. There is however, a paucity of work seeking to determine the impact or linkages between the $\mathrm{AO}$ and Caribbean weather. This study and others serve to fill that knowledge gap. Figure 7 shows the trend in the AOI over the research period and the web source where the data was acquired.

A positive AOI indicates stronger winds associated with the polar vortex which results in cold air closer to the Polar region while a negative AOI is an indication of weaker westerlies associated with the Polar vortex resulting in cold arctic air moving further south and storms tracts remaining further south. According to [35] in his investigation of the relationship between ENSO, the Pacific North American pattern (PNA), the $\mathrm{AO} / \mathrm{NAO}$, weather and climate variability during the Florida dry season. A 50\% chance of an extreme freeze over Daytona Beach Florida is likely during boreal winter when extreme values of negative 


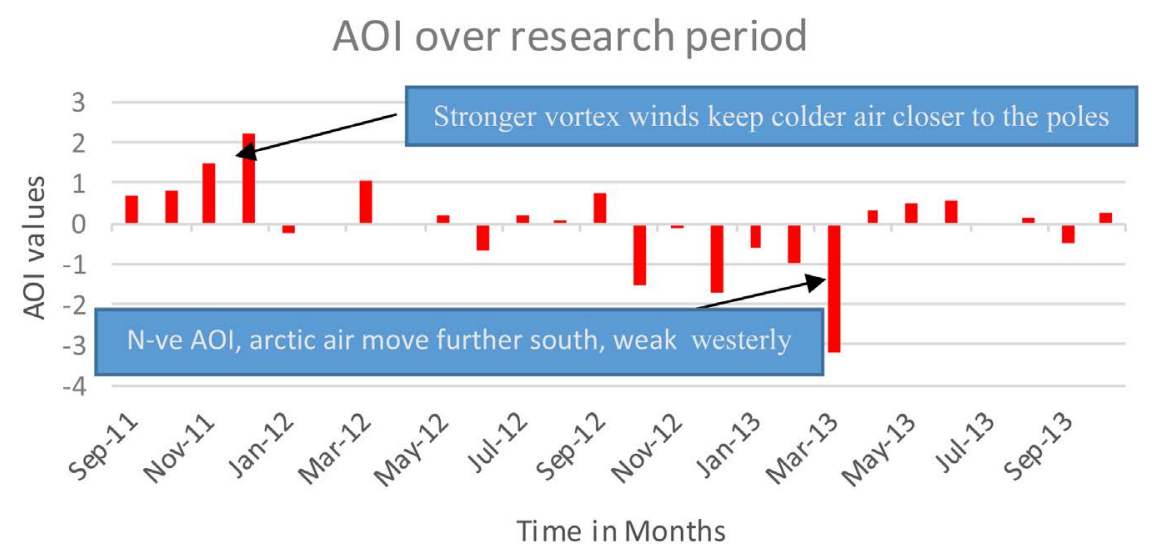

Figure 7. Arctic oscillation index trend over study period. Data from: http://www.cpc.ncep.noaa.gov/products/precip/CWlink/daily_ao_index/ao.shtml.

AO occur, while a $0 \%$ chance of extreme freeze over is likely when extreme values of positive AO occur. We also suggest that during the episodic freeze overs over Florida that the frontal systems that trigger these events are likely to also affect the central Caribbean and Jamaica.

\subsubsection{Summary}

Depending on the phase and severity of these indices researchers have shown that the Caribbean can be impacted by large-scale climate phenomena. What is also clear is that a connection has been made between large-scale climate phenomena centred over distant regions and the Caribbean but there has been no attempt that the author recognized after review the available literature to link these with cosmic ray muon flux over the Caribbean. Importantly the production of cosmic ray muon is initiated in the lower stratosphere and the flux of muons is regulated by the depth of the atmosphere whose expansion and contraction is regulated by the temperature in the lower stratosphere and upper troposphere. Several randomly chosen climate phenomena were used along with a randomly chosen period to determine the possible teleconnection. The method, results and conclusions follow.

\section{Data, Instrumentation and Method}

\subsection{Data}

The data captured was for the period September 2011 to October 2012. The bin width used in this study was the 5-minute bin width and consequently, the data for this entire period was referred to as Muon5. This dataset subsequently divided into two sections. The first section (Sep 2011-Oct 2012) was used as the control period for the investigation. This period involved the capture and collection of cosmic ray muons and all other particles impinging on the detector and so was referred to as cosmic ray muon flux plus (CMF+). During the second period (Nov 2012-Sep 2013) the detector was adjusted to be sensitive to cosmic-ray muons only. The data for this period will be referred to as cosmic ray muon flux 
(CMF). The QuarkNet 6000 cosmic-ray muon detector located at the Mona Campus of the University of the West Indies was the only detector used. The gathering of the data for the period Sep 2011, to October 2012 was done using the single fold coincidence counting method. Coincidence counting is the electronic means of measuring the number of sub-atomic particles that impact a detector. Coincidence is defined as an event where more than one counter shows a signal within a time interval of one (1) microsecond or less [36]. When the system is set to single fold counting, all particles hitting an assigned scintillator are registered. This single-fold method was changed to double fold or 2-fold coincidence in November 2012. The change was made to allow for the isolation of muons only. The detector used for this study has 4 counters of which the top two were assigned for counting. With a 2-fold coincidence, the cosmic ray detector determines that particles are muons when both counters register hits within stipulated a period. The data acquisition board for the QuarkNet6000 has a 10 ns resolution and absolute accuracy of 100 ns. Other datasets from the US National Weather Service/ USA Nation Ocean and Atmospheric Administration (NOAA) and the Meteorological Service, Jamaica were also used. Table 1 below indicates the large-scale phenomena and the name of the indices used in this study.

In considering the teleconnection between base points, the geomagnetic cut off rigidity (GCOR) values are also important. This is a quantitative measure of the shielding provided by the Earth's magnetic field [37]. Both [37] and [38] highlighted the importance of this parameter and argued that the GCOR is an ordinate that describes the charge particle access at any location within the magnetosphere. [37] further stated that cut off rigidity helps to predict the energetic charged particle transmission through the magnetosphere to a specific location as a function of direction. The GCOR values are similar for locations at similar latitudes. For example, the cut off rigidity for Mexico City $\left(19.32^{\circ} \mathrm{N}\right.$ and $99.2^{\circ} \mathrm{W}$ ) was 8.18 Giga Volts $(\mathrm{GV})$, while in Kingston, Jamaica $\left(18.0^{\circ} \mathrm{N}\right.$ and $76.44^{\circ} \mathrm{W}$ ) was $8.19 \mathrm{GV}$. However, when compared with geomagnetic rigidity for higher latitudinal regions, the value was very different. For example, the value

Table 1. Large scale climate phenomena and their indices.

\begin{tabular}{ll}
\hline Climate Phenomena & Nomenclature \\
\hline El Nino (EN), La Nina (LN) & Oceanic Nino Index (ONI), \\
Southern Oscillation (SO) & Southern Oscillation Index (SOI) \\
North Atlantic Oscillation & North Atlantic Oscillation Index (NAOI) \\
Quasi-Biennial Oscillation & Quasi-Biennial Oscillation Index (QBOI) \\
Arctic Oscillation (AO) & Arctic Oscillation Index (AOI) \\
Cosmic-ray muon flux 5 min bin width & Muon5 (total period) \\
Cosmic-ray muon flux 5 plus noise & CMF+ \\
Cosmic-ray muon flux 5 only & CMF
\end{tabular}


for Oulu in Finland $\left(65.01^{\circ} \mathrm{N}, 25.47^{\circ} \mathrm{E}\right)$ was $0.68 \mathrm{GV}$. In the Caribbean, the values for the geomagnetic rigidity ranged from $12.33 \mathrm{GV}$ for Port of Spain Trinidad $\left(10.66^{\circ} \mathrm{N}, 61.5^{\circ} \mathrm{W}\right)$ to $7.81 \mathrm{GV}$ at Guantanamo Bay, Cuba $\left(19.9^{\circ} \mathrm{N}\right.$ and $\left.75.1^{\circ} \mathrm{W}\right)$. The geomagnetic cut off rigidly does not change drastically unless there is significant change in the earth's magnetic field. Table 2 below shows the geomagnetic cut off rigidity over a 15 -year period for coordinate points within the severe weather grid (SWG), which was used as the base point region.

The cut off rigidity values were generated with a reference year of 2010 using the cutoff rigidity calculator from the website

http://cosmos.hwr.arizona.edu/Util/rigidity.php accessed 01/11/2018 [39]. According to [40] who accessed geomagnetic cut off rigidities (GCOR) of several centuries, GCOR are not fixed but have changes that are nonlinear, are highest near the equator with increases in the order of $1 \%$ per annum over the north Atlantic Ocean and decreases $>0.5 \%$ per annum in the south Atlantic.

Another large-scale climate phenomenon of interest was the sudden stratospheric warming (SSW), which was not considered in this study. However, the SSW does not have an index but have been found to be positively correlated to cosmic-ray muon flux in the lower stratosphere and inversely correlated to Jamaican dry season rainfall in separate studies.

\subsection{Instrumentation}

In the absence of a Caribbean-wide cosmic-ray muon detection network, a single detector was used in this study. The QuarkNet 6000 cosmic-ray muon detector is similar to the one used by [41] and further described in [42]. The various pieces of the detector are shown in Figure 8.

In Figure 8, the actual apparatus used during the investigation is presented. This apparatus involves the electronic devices and structural material to enable a stable setup of the cosmic ray muon detector as described by [41] and [43]. This system provided a cost-effective method for obtaining high-quality data based on coincidence theory when compared to a more sophisticated and expensive counterpart. The detector involves $10 \times 12$ inches $(25.4 \times 30.48 \mathrm{~cm})$ plastic scintillators, separated 7.5 inches $(19.05 \mathrm{~cm})$ apart, these are shown here as an

Table 2. Jamaican severe weather grid and geomagnetic cutoff rigidity cradle 1995, 2000, 2005 and 2010.

\begin{tabular}{ccccc}
\hline \multicolumn{5}{c}{ Severe Weather Grid Geomagnetic Cut-off Rigidity } \\
\hline SWG Coordinates & 1995 & 2000 & 2005 & 2010 \\
\hline $21 \mathrm{~N} / 83 \mathrm{~W}$ & 7.21 & 7.26 & 6.64 & 6.82 \\
$21 \mathrm{~N} / 71 \mathrm{~W}$ & 7.64 & 7.23 & 7.87 & 7.87 \\
$14 \mathrm{~N} / 83 \mathrm{~W}$ & 9.61 & 9.61 & 9.61 & 9.63 \\
$14 \mathrm{~N} / 71 \mathrm{~W}$ & 9.89 & 10.01 & 10.09 & 10.27 \\
$18 \mathrm{~N} / 76 \mathrm{~W}$ & 7.97 & 8.04 & 8.13 & 8.2 \\
\hline
\end{tabular}




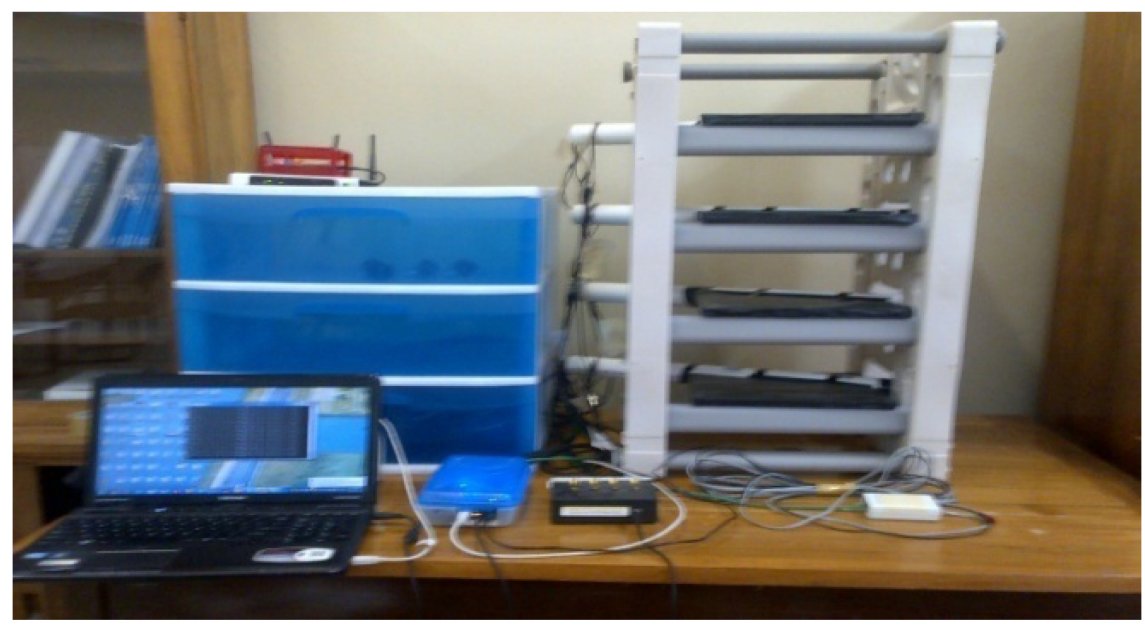

Figure 8. UWI cosmic-ray muon detection apparatus.

array of black horizontal plates to the right of the figure. The photomultiplier tubes (PMT) are then joined to the scintillator to form a paddle. The other visible parts are the power distribution unit (PDU), the global positioning system (GPS), the modem, a Raspberri Pi miniature computer and a laptop computer. The miniature computer and laptop were used to remotely access and view the data collected by the detector. This detector is similar to the type used in [41], however, in [41] a method where the orientation of the detector could be varied to determine the direction of muons impacting the detector was also employed. In current study, the detector orientation was fixed. There were no modifications to the primary equipment setup, however, structural material was used only to house and secure the detector parts. Section 3.3 explains the method used to arrive at our conclusion.

\subsection{Method}

As indicated in the previous sections there are many atmospheric and oceanic oscillations that impact meteorological and climatic systems. The advent of the field of muon Diagnostics facilitated the exploration of a link between cosmic-ray muon flux, atmospheric and extra atmospheric phenomena. This study is therefore motivated by: 1) the increasing view in the research community that cosmic-rays play an important role in our changing atmospheric and climate systems, 2) the paucity of information about the behavior of this ubiquitous sub-atomic particle, its intensity, impact and relationship with meteorological and climatic phenomena over the Caribbean, and, 3) the need to pursue additional explanations to those used for Caribbean climate and weather variability.

The cosmic-ray muon flux data captured were first divided into several bin widths, ranging from 5-minute to 24-hours. The 5-minutes bin width (here after Muon5) matched the shortest frequency of observations being used at the time of the study and allowed for an observation index similar to that mandated by the World Meteorological Organization (WMO) to be developed. Three (3) types of indices were developed, these were 1) the Muon5 values which was an 
averaged of the period 5 minutes before and after each hour-then used to represent a 10 minute average for each hour. These top-of-the-hour observations were then sampled every 6 hours in accordance with the WMO main observation hours. The WMO identifies the main observation synoptic hours as 0000 , 0600, 1200 and 1800 UTC. The identification used to represent these indices were $\mathrm{Mu} 00 \mathrm{Z}, \mathrm{Mu} 06 \mathrm{Z}, \mathrm{Mu} 12 \mathrm{Z}$ and Mu18Z respectively, 2) the average of the Muon5 over a 24-hour period (Mu5D) and, 3) Muon5 monthly was the average of the Muon5 over the month (Mu5M).

The initial assessment of the observed muon flux data was done using the applications on the http://I2U2.org website for quality control and for separation of the data into the various bin widths. The quality control process also involved visual inspection of the data for possible abnormal fluctuations, especially during the time when there were disruptions to the public electricity supply at the UWI. Teleconnections between large-scale climate phenomena and cosmic ray muon flux (CMF) were based on the strength of the correlation coefficients generated (using SigmaPlot 12.5 statistical software) between the indices for large-scale climatic phenomena and the monthly Muon5 (Mu5M). The indices for the randomly chosen phenomena included the Quasi-Biennial Oscillation Index (QBOI), the Oceanic Nino Index (ONI), the Southern Oscillation Index (SOI), the North Atlantic Oscillation Index (NAOI) and the Arctic Oscillation Index (AOI). In order to determine the possible existence of teleconnections, the following 5 steps were carried out:

1) Designate a base point as a sub-region of the Caribbean.

2) Perform quality control and separation of cosmic ray muon flux data using http://I2U2.org.

3) Acquire the large scale climate phenomena indices from various sources.

4) Assess the large-scale phenomena over the long term among each other.

5) Perform the correlation analyses between the large-scale indices, including Muon5 monthly (Mu5M), over the study period. The study period was divided into a control and test period. The control period involved unfiltered cosmic-ray muon flux gathered over the period Sep 2011-Oct 2012 (CMF+) while the test period involved cosmic-ray muon flux only (CMF) for the period Nov 2012-Sep 2013.

This unfiltered period is being viewed as having as much as 70 percent of the subatomic particles measured at the surface being muons [40]. The CMF represented a period when 100 percent of the data collected were muons. The strength of the resulting correlation was then used to indicate the link or possible teleconnection between the cosmic ray muon flux (CMF+ and CMF) and the large scale climate indices. In current study, we acknowledge that other atmospheric and extra-atmospheric factors are likely to have played a role in the enhancement or suppression of the influence of the large-scale climatic phenomena used and their subsequent the relationship between the monthly Muon5 (Mu5M), [44]. This wider examination was not the focus of this study but will be pursued later. Since rainfall is a fundamental atmospheric variable, the mean monthly 
rainfall over the island was therefore used to evaluate the strength of the relationship between the climatic indices and cosmic-ray muon flux for the base point.

\section{Results}

\subsection{Connections between Climate Phenomena}

The climate Normals for the period Jan 1961-Dec 1990 are considered by the World Meteorological Organization (WMO) as reference normals for climate change analysis [45]. An examination of the correlation statistics before and after Dec 1990 confirmed the strength of the correlations among the climate indices used. Table 3 below reveals that the strongest correlation coefficients were between the ONI and the SOI $(-0.75)$ which represents the ENSO phenomena, and the NAOI and the AOI (0.63) representing the link between NAO-AO phenomena over the period 1991-2015. This was generated at the 95\% confidence level. The relationship between other indices were very weak for this period.

Over the period Jan 1991-Dec 2015 the stratospheric QBOI was uncorrelated with all the other climatic indices used. The strength of these correlations were used as an indication of the level of influence of the climate phenomena over their source region and also indicate the influence they are likely to have on cosmic-ray muon flux over the base point region. The following Section 4.2 therefore describes the correlations strengths for the unfiltered cosmic-ray muon flux (Sep 2011-Oct 2012), the cosmic-ray muon flux filtered during the period Nov 2012-Sep 2013 and with the climate indices used.

\subsection{Teleconnections with Cosmic-Ray Muon Flux}

Significant information can be retrieved from underground and underwater muon investigations. For example, a direct correlation has been shown to exist between underground muon intensities and muon production in the stratosphere due to the behaviour of Pions and Kaons to temperature changes, [46]. [47] has shown that the rate of high energy cosmic-ray muons are strongly correlated to upper air temperature during short term atmospheric events know as sudden stratospheric warmings. This leads to increase muon rate when Pion and Kaon decay, rather than interact as it is the decay process that lead to muons being formed. [48] also argues that there is a strong connection between sudden

Table 3. Climate indices correlation strength 1991-2015.

\begin{tabular}{cccccc}
\hline Climate Phenomena & QBOI & SOI & AOI & ONI & NAOI \\
\hline QBOI & 1 & & & & \\
SOI & 0.02 & 1 & & & \\
AOI & 0.06 & 0.07 & 1 & & \\
ONI & 0.05 & -0.75 & -0.03 & 1 & \\
NAOI & 0.06 & 0.06 & 0.63 & 0.028 & 1 \\
\hline
\end{tabular}


stratospheric warmings (SSW) and extensive changes throughout the earth's atmosphere. These changes affect, for example, the atmospheric temperature (with increases of up to $50^{\circ} \mathrm{C}$ ), winds (by changing wind direction and speed) and electron density from the earth surface to the thermosphere. They further argue that there is a connection between space weather and SSWs and that SSWs are a significant source of variability in the earth's thermosphere and ionosphere (especially the high ionospheric conductivity regions of the equatorial low latitudes).

Since the muons are the most abundant charged particle at the earth's surface composing up to 70 percent of cosmic-rays [43], [46] and [49], a strong argument can be made for teleconnection between the various atmospheric phenomena, not only during the stratospheric sudden warming periods but for all seasons. This is so since cosmic ray muon flux is impacted by the changes in temperature and pressure during the different seasons. By traversing the atmosphere at the nanoscale it is a prime candidate to be used for baro-thermal assessment. [22] also argues that although teleconnection patterns often evolve on a sub-monthly timescales, their spatial patterns are typically characterized in monthly and seasonal data. The results are presented in Table 4 and Table 5 below for the respective periods.

In Table 4, the values generated, revealed significant correlation coefficient values (CCV) between all the indices. All the CCVs for the CMF+ were positive except for the ONI which was negatively correlated with all other large-scale climatic indices including the unfiltered muon flux. A similar correlation assessment

Table 4. CMF+ vs climate indices Oct 2011-Oct 2012.

\begin{tabular}{ccccccc}
\hline Phenomena & QBOI & SOI & AOI & ONI & NAOI & CMF+ \\
\hline QBOI & 1.00 & & & & & \\
SOI & 0.55 & 1.00 & & & & \\
AOI & 0.47 & 0.69 & 1.00 & & & \\
ONI & -0.94 & -0.73 & -0.59 & 1.00 & & \\
NAOI & 0.68 & 0.80 & 0.78 & -0.83 & 1.00 & \\
CMF+ & 0.87 & 0.43 & 0.58 & -0.85 & 0.61 & 1 \\
\hline
\end{tabular}

Table 5. CMF vs climate indices Nov 2012-Sep 2013.

\begin{tabular}{ccccccc}
\hline Climates Indices & QBOI & SOI & AOI & ONI & NAOI & CMF \\
\hline QBOI & 1.00 & & & & & \\
SOI & 0.48 & 1.00 & & & & \\
AOI & 0.38 & -0.04 & 1.00 & & & \\
ONI & -0.66 & -0.01 & -0.22 & 1.00 & & \\
NAOI & 0.51 & -0.26 & 0.80 & -0.55 & 1.00 & \\
CMF Muon5 & -0.67 & -0.05 & -0.52 & 0.55 & -0.59 & 1.00 \\
\hline
\end{tabular}


was conducted on the Nov 2012-Sep 2013 period when only muons were filtered. The results are outlined in Table 5.

The results in Table 5 revealed a significantly different set of values, some of which was totally opposite to the control period. These would therefore be the best indication of the teleconnection strength between the base point region and the source region of the climate indices used. When the correlation coefficients of indices that had strong correlation over the period Jan 1991-Dec 2015 were compared with those during the study period, only very small differences were observed. Table 6 below explains the comparison.

The coefficients in Table 6 shows a similarity between the indices in CMF+ period and the broader 1991-2015 period since ONI-SOI and NAOI-AOI correlations being in the same range. During the CMF period however the SOI correlation values were all negative and weak however the ONI-SOI $(-0.01)$ was uncorrelated while the NAOI-AOI value was positive and strong (0.80). A variation in strength and differences in the sign of most of the correlation coefficients for the climate indices used was also observed during the CMF period. These variations in the sign and strength of the coefficients, we suggest, point to the behaviour and level of influence of the climate phenomena on the muon flux over our region. Table 7 below explains more clearly the contrast when the CMF+ and CMF was correlated to the climate indices.

A distinctive change in the sign of the correlation coefficients from positive values for the $\mathrm{CMF}+$ to negative values for the CMF for most indices. The change from positive to negative may be attributable to greater sensitivity of the cosmic-ray muon flux, as well as changes in the behavior of the large-scale climate indices during the two separate periods.

\section{Summary}

Oceanic and atmospheric oscillations are reflected in various parameters such as wind, temperature pressure and density over different regions globally. The wind direction as well as the speed is of significant importance especially in the upper troposphere and lower stratosphere. [50] suggest that the stratospheric-

Table 6. Comparing highly correlated indices 1991-2015 with study period.

\begin{tabular}{ccccccc}
\hline \multirow{2}{*}{$\begin{array}{c}\text { Climates } \\
\text { Indices }\end{array}$} & \multicolumn{2}{c}{ Jan 1991-Dec 2015 } & \multicolumn{2}{c}{ CMF+(Sep 2011-Oct 2012) } & \multicolumn{2}{c}{ CMF (Nov 2012-Sep 2013) } \\
\cline { 2 - 6 } & ONI & NAOI & ONI & NAOI & ONI & NAOI \\
\hline SOI & -0.75 & & -0.73 & & -0.01 & \\
AOI & & 0.63 & & 0.78 & & 0.80 \\
\hline
\end{tabular}

Table 7. Cosmic ray muon flux versus climate indices Sep 2011-Sep 2013.

\begin{tabular}{cccccc}
\hline Study Period Climates Indices & QBOI & SOI & AOI & ONI & NAOI \\
\hline CMF+ (Sep 2011-Oct 2012) & 0.87 & 0.43 & 0.58 & -0.85 & 0.63 \\
CMF (Nov 2012-Sep 2013) & -0.67 & -0.05 & -0.52 & 0.55 & -0.59 \\
\hline
\end{tabular}


tropospheric coupling can result in weak vortex events. This coupling would have an impact on the El Nino, La Nina, SO, QBO, NAO, AO and other climate phenomena which subsequently influence weather conditions at the surface. [29] suggest that climate change promotes coupling between large-scale enhanced deep convection and that the emergence of this relationship coincides with the recent cooling trend in the lower equatorial stratosphere and the warming trend in the upper equatorial troposphere. [47] and [51] however argued that an increase in temperature in the stratosphere results in a decrease in air density, which reduces the chances of interaction of Pions and Kaons, which then results in a greater portion decaying to form muons. This, therefore can result in a higher muon flux at the earth's surface. In this work, we also argue that the observed downward trend in naturally occurring unfiltered cosmic-ray muon flux $(C M F+)$ and cosmic ray muon flux (CMF) isolated from the background noise also implies general cooling in the upper troposphere and or lower stratosphere. The observed trend in muon flux over the base point within the Caribbean also coincides with lower solar activity over the past 30 plus years which coincides with a 30 year cooling trend in the lower stratosphere and upper troposphere, a 30 positive trend in the NAO and a general reduction in rainfall over the Caribbean over the past 20 - 30 years. This link to the lower stratosphere is very important since this is the area of initial muon production. [29] also argued that a link exists between the NAO, the QBO and large regions of enhanced deep convection in the tropics known as the madden Julian oscillations (MJO). Interannual variation of MJO activity, due to the QBO they argued, is much greater than the variation due to the tropical sea surface temperatures, which is the usual source for interannual variation of tropical convective activity. This tropical connectivity also plays an important role as control mechanisms for the flux of muons to the surface [2].

The changes in phase of climate indices (representing a base point) from positive, neutral or negative, indicate the level of influence on weather, that is, their influence on the parameters such as temperature, pressure, wind and rainfall. More storms are therefore likely over the Caribbean during the positive phase of $\mathrm{NAO}$ and less during the negative phase. More storms are also likely during the La Nina phase over the Caribbean and less storms during El Nino phase. More storms are likely when the QBO is in its westerly (QBOW) or positive phase than when the $\mathrm{QBO}$ is easterly (QBOE) or its negative phase. The convective activity and presence of storms affect the depth of the atmosphere which also plays an important role in the flux of muons over any region. An assessment of the study period using 4 separate 6-months time spans was carried out in order to capture the most dominant behaviour of each climatic index. Table 8 outlines the dominant impact of the climatic index over the 4 separate 6-month impact periods.

The assessment revealed various changes in phase over the period, however the cosmic ray muon flux being the only one remaining unchanged during period 1 and period 2. This consistent tendency regardless of the change in other 
Table 8. Climate Indices phase characterization and likely impact during study period.

\begin{tabular}{|c|c|c|c|}
\hline Oct 2011 to Mar 2012 & Apr 2012 to Sep 2012 & Oct 2012 to Mar 2013 & Apr 2013 to Sep 2013 \\
\hline nve ONI (coiling) & pve ONI (warm) & nve ONI (cooling) & nve ONI (cooling) \\
\hline pve SOI (cooling) & nve SOI (warm) & $\begin{array}{l}\text { pve SOI then nve SOI } \\
\text { (cooling then warm) }\end{array}$ & pve SOI (cooling) \\
\hline $\begin{array}{l}\text { pve NAOI (stronger winds, high } \\
\text { pressure gradient, stronger storms) }\end{array}$ & $\begin{array}{l}\text { nve NAO1 (lighter winds, fewer } \\
\text { weaker storms, westerlies) }\end{array}$ & $\begin{array}{c}\text { pve NAOI } \\
\text { (stronger winds, high pressure } \\
\text { gradient, stronger storms) }\end{array}$ & $\begin{array}{l}\text { pve NAOI (stronger winds, high } \\
\text { pressure gradient, stronger storms) }\end{array}$ \\
\hline nve QBOI (easterly winds, warm) & $\begin{array}{c}\text { nve QBOI } \\
\text { (easterly winds, warm) }\end{array}$ & $\begin{array}{c}\text { nve QBOI } \\
\text { (easterly winds, warm) }\end{array}$ & pve QBOI (westerly winds, cooling) \\
\hline $\begin{array}{c}\text { pve AOI } \\
\text { (cooling/strong winds) }\end{array}$ & $\begin{array}{c}\text { pve AOI } \\
\text { (cooling/strong winds) }\end{array}$ & $\begin{array}{c}\text { nve A0I } \\
\text { (warm/light winds/low pressure) }\end{array}$ & $\begin{array}{c}\text { pve AOI } \\
\text { (cooling/strong winds/High pressure) }\end{array}$ \\
\hline $\mathrm{CMF}+$ decrease (cooling) & $\begin{array}{l}\mathrm{CMF}+\text { decrease } \\
\text { (cooling) }\end{array}$ & CMF decrease (cooling) & CMF decrease (cooling) \\
\hline
\end{tabular}

NB: The description of the indices in table 2.8 was based on information gleaned from the various websites where each index was sourced, example, https://www.ldeo.columbia.edu/res/pi/NAO/.

climate indices in the muon flux was referred to as cumulative teleconnection effect or CTE. It should be noted that since no climatic variable acts independently, their impact are therefore based on one or more phenomena influencing the weather condition over any base point region, which then results in either an enhancement or suppression of weather and or the other indices. There is therefore evidence that a teleconnection may exist between the indices from the various source regions, the cosmic-ray muon flux and weather conditions within the severe weather grid (SWG). Section 6 outlines the conclusions drawn from this study.

\section{Conclusions}

The strength of teleconnection was based on the statistical correlation between indices representing climatic phenomena for incontiguous regions and a base point was investigated and discussed. The relationship between these large-scale climatic indices and two (2) periods of cosmic-ray muon flux, which was gathered consecutively from a single detector, was used for the investigation. The first period was unfiltered and composed of up to $70 \%$ cosmic-ray muon flux $(\mathrm{CMF}+)$ while the second consecutive period (the test period) was filtered using coincidence theory and thus contained only the flux of cosmic ray muons (CMF).

Based on the correlation coefficient values (CCV) generated, the following preliminary conclusions were drawn regarding teleconnection between cosmic ray muon flux and climatic indices over the Caribbean and the designated base point.

1) Based on the consistent tendency in the cosmic-ray muon flux over the base point region, regardless of changes in other climate indices used, we suggest the use of cosmic-ray muon flux as an index for the cumulative impact of other cli- 
mate indices. This cumulative impact we propose is to be referred to as the cumulative teleconnection effect which coincides with the cooling trend in the equatorial upper troposphere and the lower stratosphere. An improved Caribbean dataset is therefore needed to carry out affirmative studies. .

2) While there were variations over study period in the correlation coefficient values for various indices. The correlation coefficient values for the ONI vs SOI and AOI vs NAOI for the Jan 1991-Dec 2015 were strong and confirmed the well documented relationship between the El Nino and Southern Oscillation (EN-SO) and, Arctic and North Atlantic oscillations (AO-NAO). Over the study period the ONI-SOI was uncorrelated during the CMF period however the AOI-NAOI remained strong. Since the connection between the NAO and the Caribbean is well documented, this trend suggests the need to explore a teleconnection between cosmic ray muon flux, weather over the Caribbean and the Arctic oscillation.

3) The correlation coefficient values over the CMF+ period (Sep 2011-Oct 2012) were all positive except for the ONI which was negative while those over the CMF period (Nov 2012-Sep 2013) were all negative except for ONI which was positive. Of those climate indices that were positive during the CMF+ period the SOI was robust but not significant (0.43). This was also the case during the CMF period where the SOI was not significantly correlated $(-0.05)$. We concluded that this reduced correlation coefficient values may be partly due to the reduced intensity in cosmic-ray muon flux generally along with impact of climate phenomena. This therefore meant that the teleconnection between SOI and $C M F+$ was robust but not significant and that during the CMF period there was no teleconnection. This was likely because the source region was the farthest from the Caribbean.

4) The change in correlation coefficient values, generally from positive over the CMF+ period to negative values for the CMF period, was attributed mainly to increased sensitivity due to increased muon flux component which resulted in a phase shift. This sensitivity could also be partly due to increase instrument sensitivity as a change was made to detect muons only.

Our focus on a base point in the Caribbean region, points not only to the uniqueness of the study, but also to the need for Caribbean researchers to determine alternate mechanisms which may be impacting the region's weather and our changing climate system. Teleconnections between weather and climatic indices are therefore strongly suggested, based on the impact on constituent elements such as temperature, wind, atmospheric density and rainfall but the time is now ripe for enthusiastic assessment of impacts of an extra-atmospheric origin. A strong statistical link was also observed between the cosmic-ray muon flux observed from the data gathered at the UWI Mona with most of the large-scale indices over the study period (short term). [48] also argues that there is a strong connection between sudden stratospheric warmings (SSW) and extensive changes throughout the earth's atmosphere. Since an index is not readily available for the SSW but it has been linked to cosmic ray muon flux (CMF), 
other large scale climate phenomena and rainfall over the Caribbean, a wider data collection and deeper investigation is recommended.

\section{Conflicts of Interest}

The authors declare no conflicts of interest regarding the publication of this paper.

\section{References}

[1] Mok, H.M. and Cheng, K.M. (2001) The Day-Night Variation of Cosmic Ray Intensity at Sea Level under the Influence of Fronts and Troughs. Radiation Health Unit, Hong Kong.

[2] Marusek, J.A. (2006) The Relationship between Cosmic Rays and Hurricanes. 2nd International Conference on Global Warming and the Next Ice Age, Santa Fe, 1-17 July 2006.

[3] Worldatlas.com (2018) The 10 Tallest Peaks in the Caribbean. WorldAtlas.com. https://www.worldatlas.com/articles/the-10-tallest-peaks-in-the-caribbean-region.h $\underline{\mathrm{tml}}$

[4] Wang, C. and Lee, S. (2007) Atlantic Warm Pool, Caribbean Low-Level Jet, and Their Potential Impact on Atlantic Hurricanes. Geophysical Research Letters, 34, L02703. https://doi.org/10.1029/2006GL028579

[5] Angeles, M.E., González, J.E., Ramírez-Beltrán, N.D., Tepley, C.A. and Comarazamy, D.E. (2010) Origins of the Caribbean Rainfall Bimodal Behavior. Journal of Geophysical Research, 115, 1-17. https://doi.org/10.1029/2009JD012990

[6] Kaufman, Y.J., Boucher, O., Tanre, D., Chin, M., Remer, L.A. and Takemura, T. (2005) Aerosol Anthropogenic Component Estimated from Satellite Data. Geophysical Research Letters, 32, 2-3. https://doi.org/10.1029/2005GL023125

[7] Ng, D.H.L., Li, R., Raghavan, S.V. and Liong, S.Y. (2017) Investigating the Relationship between Aerosol Optical Depth and Precipitation over Southeast Asia with Relative Humidity as an Influencing Factor. Scientific Reports, 7, Article No. 13395. https://doi.org/10.1038/s41598-017-10858-1

[8] Marsh, N. and Svensmark, H. (2003) Galactic Cosmic Ray and El Nino-Southern Oscillation Trends in International Satellite Cloud Climatology Project D2 LowCloud Properties. Journal of Geophysical Research, 108, 4195. https://doi.org/10.1029/2001JD001264

[9] Svensmark, H. (2007) Cosmoclimatology: A New Theory Emerges. Astronomy and Geophysics, 48, 18-24. https://doi.org/10.1111/j.1468-4004.2007.48118.x

[10] Agee, E.M., Kiefer, K. and Corett, E. (2012) Relationship of Lower-Troposphere Cloud Cover and Cosmic Rays: An Updated Perspective. Journal of Climate, 25, 1057-1060. https://doi.org/10.1175/JCLI-D-11-00169.1

[11] Kavlakov, S., Elsner, J.B. and Perez-Peraza, J. (2008) A Statistical Link between Tropical Cyclone Intensification and Major Geomagnetic Disturbances. Geofísica Internacional, 47, 207-213.

[12] Barbashina, N.S., Borog, V.V., Dmitrieva, A.N., Kokoulin, R.P., Kompaniets, K.G., Petrukhin, A.A., Timashkov, D.A., Shutenko, V.V. and Yashin, I.I. (2007) Muon Diagnostics of the Earth's Atmosphere and Magnetosphere. Bulletin of the Russian Academy of Sciences: Physics, 71, 1041-1043. https://doi.org/10.3103/S1062873807070441

[13] Elsner, J. (2001) Hurricane Intensity Changes Associated with Geomagnetic Varia- 
tion. Atmospheric Science Letters, 2, 86-93. https://doi.org/10.1006/asle.2001.0040

[14] Kniveton, D.R. and Todd, M.C. (2001) On the Relationship of Cosmic Ray Flux and Precipitation. Geophysical Research Letters, 28, 1527-1530. https://doi.org/10.1029/2000GL012536

[15] Visbeck, M.H., Hurrell, J.W., Polvani, L. and Cullen, H.M. (2001) The North Atlantic Oscillation: Past, Present, and Future. PNAS, 98, 12876-12877. https://doi.org/10.1073/pnas.231391598

[16] Schwadron, N.A., Blake, J.B., Case, A.W., Joyce, C.J., Kasper, J., Mazur, J., Petro, N., Quinn, M., Porter, J.A. and Smith, C.W. (2014) Does the Worsening Galactic Cosmic Radiation Environment Observed by CRaTER Preclude Future Manned Deep Space Exploration? Space Weather, 12, 622-632. https://doi.org/10.1002/2014SW001084

[17] Shaviv, N.J. (2006) Cosmic Rays and Climate. PhysicaPlus.

[18] Campton, A.H. (1932) Variation of the Cosmic Rays with Latitude. Physics Review, 41, 111. https://doi.org/10.1103/PhysRev.41.111.2

[19] Tezari, A., Mavromichalaki, H., Katsinis, D., Kanellakopoulos, A., Kolovi, S., Plainaki, C. and Andriopoulou, M. (2016) Latitudinal and Longitudinal Dependence of the Cosmic Ray Diurnal Anisotropy during 2001-2014. Annales Geophysicae, 34, 1053-1068. https://doi.org/10.5194/angeo-34-1053-2016

[20] Marsh, N. and Svensmark, H. (2000) Cosmic Rays, Clouds, and Climate. Space Science Reviews, 94, 215-230. https://doi.org/10.1007/978-94-010-0888-4_21

[21] Svensmark, H. and Friis-Christensen, E. (1997) Variation of Cosmic Ray Flux and Global Cloud Coverage-A Link in Solar-Climate Relationships. Journal of Atmospheric Physics, 59, 1225-1232. https://doi.org/10.1016/S1364-6826(97)00001-1

[22] Nigam, S. and Baxter, S. (2015) Teleconnections. In: Encyclopedia of Atmospheric Sciences, Elsevier Ltd., London, 90-109. https://doi.org/10.1016/B978-0-12-382225-3.00400-X

[23] Taylor, M.A., Enfield, D.B. and Chen, A.A. (2002) Influence of the Tropical Atlantic versus the Tropical Pacific on Caribbean Rainfall. Journal of Geophysical Research, 107, 3127. https://doi.org/10.1029/2001JC001097

[24] Meteorological Service, Jamaica (1990) Severe Weather Orders. Meteorological Service, Kingston.

[25] Chen, A.A. and Taylor, M.A. (2002) Investigating the Link between Early Season Caribbean Rainfall and the El Niño + 1 Year. International Journal of Climatology, 22, 87-106. https://doi.org/10.1002/joc.711

[26] Jury, M., Malmgren, B.A. and Winter, A. (2007) Subregional Precipitation Climate of the Caribbean and Relationships with ENSO and NAO. Journal of Geophysical Research, 112, D16107. https://doi.org/10.1029/2006JD007541

[27] Baldwin, M.P., Gray, L.J., Dunkerton, T.J., Hamilton, K., Haynes, P.H., Randel, W.J., Holton, J.R., Alexander, M.J., Hirota, I. and Horinouchi, T. (2001) The Quasi-Biennial Oscillation. Reviews of Geophysics, 39, 179-229. https://doi.org/10.1029/1999RG000073

[28] Gray, W.M. (1984) Summary of 1984 Atlantic Seasonal Tropical Cyclone Activity and the Verification of Author's Forecast Colorado State University.

[29] Klotzbach, P., Abhik, S., Hendon, H.H., Bell, M., Lucas, C., Marshall, A.G. and Oliver, E.C.J. (2019) On the Emerging Relationship between the Stratospheric Quasi-Biennial Oscillation and the Madden-Julian Oscillation. Scientific Reports, 9, Article No. 2981. https://doi.org/10.1038/s41598-019-40034-6 
[30] Chu, P.-S. (2004) ENSO and Tropical Cyclone Activity. In: Murnane, R.J. and Liu, K.-B., Eds., Hurricanes and Typhoons, Past, Present and Future, Columbia University Press, New York, 323.

[31] Charlery, J., Nurse, L. and Whitehall, K. (2006) Exploring the Relationship between the North Atlantic Oscillation and Rainfall Patterns in Barbados. International Journal of Climatology, 26, 819-826. https://doi.org/10.1002/joc.1334

[32] Hurrell, J.W. (1995) Decadal Trends in the North Atlantic Oscillation: Regional Temperatures and Precipitation. Science, 269, 676-679. https://doi.org/10.1126/science.269.5224.676

[33] Thompson, D.W.J. and Wallace, J.M. (1998) The Arctic Oscillation Signature in the Wintertime Geopotential Height and Temperature Fields. Geophysical Research Letters, 25, 1297-1300. https://doi.org/10.1029/98GL00950

[34] Baldwin, M.P. and Dunkerton, T.J. (1999) Propagation of the Arctic Oscillation from the Stratosphere to the Troposphere. Journal of Geophysical Research: Atmospheres, 104, 30937-30946. https://doi.org/10.1029/1999JD900445

[35] Hagemeyer, B.C. (2007) The Relationship between ENSO, PNA, and AO/NAO and Extreme Storminess, Rainfall, and Temperature Variability during the Florida Dry Season: Thoughts on Predictability and Attribution. Melbourne NOAA/National Weather Service, Melbourne.

[36] Bonolis, L. (2011) Walther Bothe and Bruno Rossi: The Birth and Development of Coincidence Methods in Cosmic-Ray Physics. American Journal of Physics, 79, 1133. https://doi.org/10.1119/1.3619808

[37] Smart, D.F. and Shea, M.A. (2005) A Review of Geomagnetic Cutoff Rigidities for Earth-Orbiting Spacecraft. Advances in Space Research, 36, 2012-2020. https://doi.org/10.1016/j.asr.2004.09.015

[38] Chu, W. and Qin, G. (2016) The Geomagnetic Cutoff Rigidities at High Latitudes for Different Solar Wind and Geomagnetic Conditions. Annales Geophysicae, 34, 45-53. https://doi.org/10.5194/angeo-34-45-2016

[39] Thébault, E., Finlay, C.C., Beggan, C.D., Alken, P., Aubert, J., Barrois, O., Bertrand, F., Bondar, T., Boness, A. and Brocco, L. (2015) International Geomagnetic Reference Field: The 12th Generation. Earth, Planets and Space, 67, 79. https://doi.org/10.1186/s40623-015-0228-9

[40] Smart, D.F. and Shea, M.A. (2003) Geomagnetic Cutoff Rigidity Calculations at 50-Year Intervals between 1600 and 2000. 28 th International Cosmic Ray Conference, Tsukuba, 31 July-7 August 2003, 4201-4203.

[41] Bachri, A., Grant, P.C. and Goldschmidt, A. (2010) Analysis of Gamma Rays and Cosmic Muons with a Single Detector. Journal of the Arkansas Academy of Science, 64, 27-32.

[42] Bektasoglu, M. and Arslan, H. (2013) Investigation of the Zenith Angle Dependence of Cosmic-Ray Muons at Sea Level. Pramana, 80, 837-846. https://doi.org/10.1007/s12043-013-0519-2

[43] Rylander, J., Jordan, T. and Paschke, J. (2010) QuarkNet Cosmic Ray Muon Detector User's Manual.

[44] Mendoza, B. (2011) The Effects of Space Weather on Hurricane Activity. In: Lupo, A., Ed., Recent Hurricane Research Climate: Dynamics, and Societal Impacts, IntechOpen, London, 85-102. https://doi.org/10.5772/14070

[45] WMO-No 1203 (2017) WMO Guidelines on the Calculation of Climate Normals. In: Purpose, CH-1211, Chairperson, Publications Board World Meteorological Or- 
ganization (WMO), Geneva, 2.

[46] Arslan, H. and Bektasoglu, M. (2013) Geant4 Simulation Study of Deep Underground Muons: Vertical Intensity and Angular Distribution. Advances in High Energy Physics, 2013, Article ID: 391573. https://doi.org/10.1155/2013/391573

[47] Osprey, S., Barnett, J., Smith, J., Adamson, P., Andreopoulos, C., Arms, K.E., Armstrong, R., Auty, D.J., Ayres, D.S. and Baller, B. (2009) Sudden Stratospheric Warmings Seen in MINOS Deep Underground Muon Data. Geophysical Research Letters, 36, L05809. https://doi.org/10.1029/2008GL036359

[48] Pedatella, N.M., Chau, J.L., Schmidt, H., Goncharenko, L.P., Stolle, C., Hocke, K., Harvey, V.L., Funke, B. and Siddiqui, T.A. (2018) How Sudden Stratospheric Warming Affects the Whole Atmosphere. https://doi.org/10.1029/2018EO092441

[49] Rochester, G.D. (1962) Cosmic Rays and Meteorology. Royal Metetorological Society, 88, 369-381. https://doi.org/10.1002/qj.49708837802

[50] Mitchell, D.M., Gray, L.J., Anstey, J., Baldwin, M.P. and Charlton-Perez, A.J. (2013) The Influence of Stratospheric Vortex Displacements and Splits on Surface Climate. Journal of Climate, 26, 2668-2682. https://doi.org/10.1175/JCLI-D-12-00030.1

[51] Adamson, P., Andreopoulos, B.C., Arms, K.E., Armstrong, R., Auty, D.J., Ayres, D.S., Backhouse, C., Barnett, J., Barr, G., Barrett, W.L. and Becker, B.R. (2010) Observation of Muon Intensity Variations by Season with the MINOS Far Detector. 